\title{
CONVERSANDO SOBRE NOVAS PRÁTICAS PARA - QUEBRAR PRECONCEITOS EM RELAÇÃO AOS POVOS INDÍGENAS
}

Ketlen Lima de Souza ${ }^{1}$

Selmo Azevedo Apontes ${ }^{2}$

COLLET, C.; PALADINO, M.; RUSSO, K. Quebrando preconceitos: subsídios para o ensino das culturas e histórias dos povos indígenas. Rio de Janeiro: Contra Capa Livraria; Laced, 2014.

Algumas vezes, as mudanças de dispositivos legais educacionais em relação à alguma temática para propor novos comportamentos de respeito, de uma convivência para harmonia das relações interétnicas, é um importante passo. Mas a legislação por si mesma não resolve a problemática, como no caso do enfrentamento a práticas social e culturalmente construídas, tais como as questões afro e indígena. A legislação é apenas um dos passos. Os demais requerem ações efetivas, planejadas, direcionadas para um público, como é o caso de subsídios para formação de professores do Ensino Fundamental e Médio.

Sabemos que, na área de pesquisa acadêmica, muita coisa vem sendo feito nas últimas três décadas, no tocante aos estudos da temática dos formadores do povo e da cultura brasileira. No entanto, esses materiais acadêmicos necessitam chegar à base do núcleo formativo - os professores da educação: fundamental e médio - para que se possa gestar, a partir de novas práticas educativas, um novo comportamento: novas relações de respeito ao diferente e convívio com o diverso. Afinal, foram esses dois núcleos os grandes formadores da cultura brasileira, e nada mais justo que se conheçam as trajetórias históricas para se entender como é o comportamento social em relação ao negro e ao índio, e de como esse comportamento é o resultado de uma construção histórica. E se é uma construção, através do sistema educativo, pode ser construído, também, novas práticas e novas relações.

O livro das autoras Célia Collet, Mariana Paladino e Kelly Russo, publicado no Rio de Janeiro pela Contra Capa Livraria e LACED - Laboratório de Pesquisas em Etnicidade Cultura e Desenvolvimento - da UFRJ, no ano de 2014, com 109 páginas, é uma das construções finais do trabalho de pesquisa, prática docente e da extensão universitária das mesmas, partindo da crítica ao modo como se aprende/ensina sobre Culturas e Histórias Indígenas nas salas de aulas do nosso país. Esse modo, por sua vez, corresponde a uma prática ultrapassada que remonta os mesmos processos utilizados no período de 60 a 80 anos atrás.

1 Instituição: Universidade Federal do Acre, Orcid: https://orcid.org/0000-0001-5780-6214, E-mail: ketlima17@gmail.com 2 Instituição: Universidade Federal do Acre, Orcid: https://orcid.org/0000-0001-8985-0762, E-mail: selmoapontes@gmail.com 
Uma prática docente ultrapassada apenas reafirma o preconceito e estereótipos construídos, moldados e reforçados ao longo da história. Entre esses estereótipos estão: a representação de "índio" vinculado ao passado, na formação colonial e na constituição do "povo brasileiro"; o "índio" como algo genérico, sem levar em consideração a diversidade cultural das mais 305 etnias presentes em território nacional; além do fato de tipificar como "índios" somente aqueles que vivem, na floresta, de caça e pesca, que "atrasam" o desenvolvimento do país por ocuparem muitas terras.

Entre as práticas em sala de aula mais corriqueiras é O Dia do Índio, data "comemorativa" do calendário escolar do país, que, na maioria das vezes, é tratada de forma genérica e folclórica, realização de atividades "lúdicas" com as crianças, tais como: pintar, dançar e cantar; atividades essas que não representam nenhum povo em específico. Essas representações, muitas vezes, são romantizadas e construídas por não-índios, que estão longe de mencionar as lutas, as demandas atuais, os projetos futuros, a importância, a contribuição, o conhecimento, práticas e saberes dos povos indígenas para o Brasil atual.

As autoras estabelecem um questionamento base para entrelaçar as linhas de costura do livro, a partir disso fazem uma comparação ao mesmo tempo que criticam tais comportamentos e atitudes reproduzidas até hoje, em meio a tantas transformações educacionais: quais são as razões da reprodução de estereótipos e equívocos sobre os povos indígenas no ambiente escolar, sendo que em outras áreas do conhecimento houve mudanças significativas, em comparação a conteúdos curriculares de períodos anteriores?

Para responder à pergunta, as autoras utilizam um argumento do pesquisador e professor Antonio Carlos de Souza Lima (COLLET, PALADINO, RUSSO, 2014 apud SOUZA LIMA, 2005, p. 237), segundo o qual essas práticas ainda persistem porque existe um arquivo colonial em vigência, ou seja, tudo que conhecemos sobre os povos indígenas ainda tem vinculação com a visão construída pelo colonizador europeu, que divide os povos em "aliados" e "inimigos" das "terras portuguesas". E ainda de acordo com autor, o processo histórico forjado pelos colonizadores portugueses nada diz sobre os povos indígenas e seus saberes, mas, sim, somente registra a utilidade deles para a colonização.

Outro desdobramento atualmente reproduzido é a representação dualista do "índio": de um lado, como ingênuo e protetor da natureza, o dito bom selvagem; do outro lado, desordeiro, preguiçoso, que reclama por terras demais, o dito mau selvagem que atrapalha o desenvolvimento do país. Tais representações são reproduzidas e reforçadas por estruturas de poder, tirando os povos indígenas da constituição de agentes de sua própria história, de sua contribuição para a complexidade cultural brasileira, resultando na invisibilidade social e apagando a contribuição para história do Brasil, incluindo na história contemporânea.

Diante desse cenário de práticas retrógradas, e por perceberem que ainda não foram acrescidas novas práticas para ajudar a modificar os estereótipos, as autoras propõem o objetivo do livro: contribuir para o questionamento de tais visões deturpadas, sendo uma nova fonte de abordagem da temática indígena e a aplicação da Lei 11.645/2008, que modificou a Lei 10.639/2003, a qual tornou obrigatória o Ensino da História Africana e da Cultura da África e da Cultura Afro-brasileira, bem como o Estudo da História e das Culturas dos Povos Indígenas, nas escolas públicas e privadas de todo o país. 
A implementação da Lei 11.645/2008 está longe de ser algo que foi permitido ou que tenha sido um resultado a partir da democratização do país. Ela foi, sim, resultado da luta dos movimentos negros e indígenas por visibilidade e reconhecimento. Com isso, nessa temática, a formação de professores tornou-se prioritária, pois são agentes capazes mudanças, principalmente no tratamento qualificado da temática. Esse tratamento qualificado também contribui tanto na desconstrução de estereótipos presentes no senso comum quanto no combate ao desconhecimento, à intolerância e ao preconceito em relação aos indígenas.

As autoras seguem a reflexão de que as formações de professores, em relação às duas temáticas (Afro-brasileira e Indígena), são insuficientes, e afirmam que os recursos didáticos que os professores dispõem para o ensino das Histórias e Culturas Indígenas é menor ainda. Os livros didáticos dão pouca atenção à temática e, em muitos casos, reforçam estereótipos já mencionadas anteriormente. Outro ponto importante é que os materiais alternativos produzidos por indígenas, muitas vezes, possuem pouca circulação e divulgação.

As questões apresentadas tornaram-se incentivo para a construção do livro "Quebrando Preconceitos: subsídios para o ensino das culturas e histórias dos povos indígenas", reunindo fontes, propondo textos, filmes, sites e sugerindo propostas de atividades que se encontravam dispersas ou pouco sistematizada, fazendo uma ligação com o meio acadêmico e o meio escolar. Da mesma maneira, e tendo em vista atingir um público maior, a proposta das autoras é construir um texto de livre e fácil acesso ao professor, inclusive no modo de realizar a narrativa, tendo em vista que se tem pouco material sobre histórias e culturas dos povos indígenas.

O livro é composto de seis capítulos que desconstroem os estereótipos presentes em nossa sociedade. O capítulo um esclarece alguns termos específicos que serão usados no livro. O capítulo dois discute a ideia, apregoada por muitos, de que os índios estão acabando. $\mathrm{O}$ capítulo três questiona: o que é ser índio de verdade? O capítulo quatro aborda sobre línguas, moradias e culturas. O capítulo seguinte questiona se os índios são realmente preguiçosos e primitivos; e, por fim, o último capítulo esclarece a questão da luta pela Terra Indígena.

No início, um dos conceitos importantes é a denominação de "índio"; o erro mais clássico dos colonizadores europeus é a denominação e utilização do termo índio, pois eles, acreditando que chegaram a Índia, estenderam o termo para todo habitante que encontraram em terra. Assim, até hoje se tem essa denominação equivocada a respeito dos povos originários.

A Língua Portuguesa possui o termo indígena, que, pela norma culta, pode até parecer adequado. Contudo, ainda é um termo colonizador e genérico. Vale ressaltar que cada povo originário possui uma etnia, um pertencimento particular, e, logo, uma denominação e autodenominação. Outro termo errado e muito utilizado é a palavra "tribo", pois não representa as formas de organização política indígena em sua totalidade antes da colonização europeia. Juntamente com a palavra tribo, está arraigado também uma espécie de retirada de poderio organizacional e mantém o estereótipo de junção de pessoas sem organização. Esse fato ajuda manter estereótipo de que não há organização interna entre as etnias, esquecendo que há até, nos povos originários, as formas mais complexa de organização que são os cacicados, que reúnem grandes confederações de povos. Verifica-se, então, que é mais correto o uso do conceito de etnia ou povo indígena.

Outro ponto discutido pelas autoras é a tentativa de identificar um indígena por traços físicos, culturais ou de habitat. Essas tentativas acabam por reforçar preconceito e este- 
reótipos, além de ser uma maneira ultrapassada de "identificação". Nas constituições das identidades dos povos indígenas, como em outras sociedades humanas, acontecem ressignificados e incorporações, como também manutenção de práticas ancestrais: ou seja, não há uma interpretação de identidade estagnada e parada no tempo. Mas é uma característica identitárias em que a tradição se reconstrói ao longo do tempo. Uma das características fortes de identidade é a língua. Mas não é o único definidor de identidade, pois, em muitas etnias, com o processo brutal de colonização, ela foi destruída; mas a identidade indígena não foi apagada. E entre os critérios de identificação de um determinado povo não é o critério externo, mas está amparado na autodenominação. Contrariamente aos processos e critérios de apagamento étnico que os órgãos oficiais brasileiros, no início do século XX, em que quando um determinado povo fosse integrado à sociedade brasileira deixaria de ter seu pertencimento étnico, o processo identitário é autodenominação, ou seja: a pessoa se reconhece pertencendo a um determinado povo e tem direito de ser reconhecida por seus membros como tal. Esta concepção também é amparada pela Convenção OIT-169, convenção ratificada pelo Brasil.

Em relação à extinção ou não dos povos indígenas, as autoras fazem uma afirmação de que eles não estão acabando, mesmo com as constantes violências físicas e simbólicas que sofrem. Esse conflito numérico está amparado na concepção de estereótipos identitários dos indígenas. Este tipo de discurso contribui para manutenção de determinadas imagens e seus papéis na sociedade, pois, segundo o estereótipo, os índios romantizados estavam acabando; e os demais, já inseridos na sociedade, deixariam de ser índios: um seria os índios aldeados e aliados; e o outro, os índios bárbaros e inimigos. Os primeiros detinham a liberdade, desde que afastados dos grandes centros; os segundos eram escravizados.

Em decorrência disso, duas construções acontecem: uma, com visão romântica do indígena, aquele totalmente ligado ao passado e afastado da sociedade envolvente, com o status quo de puro e intocável, desde que isolado na floresta; outra visão é de assimilação dos indígenas à sociedade dominante, anulando todas as características étnicas do povo a que pertence. Como já foi dito, o Estado Brasileiro atuou, e atua, com políticas públicas tendo como base essas duas visões de extermínio aos povos originários.

Depois da discussão sobre como os estereótipos contribuem na questão numérica, as autoras afirmam que os povos indígenas não estão acabando. Está ocorrendo exatamente o contrário. E isso se dá por dois fatos: as etnias indígenas estão se apropriando de elementos da sociedade hegemônica, além de ter um grande movimento de retomada étnica; e o outro é a mudança de metodologia de pesquisa do IBGE (Instituto Brasileiro de Geografia e Estática) entre 2000 e 2010. Os dois fatos são importantíssimos para entender os dados reveladores do Censo 2010. Assim, verifica-se que o que está acabando ou nunca correspondeu é o estereótipo indígena construído pela sociedade brasileira.

O capítulo três discute o seguinte: o índio verdadeiro é aquele que vive pelado na floresta? O debate perpassa o Censo 2010, no qual cerca de 900 mil pessoas se autodeclararam indígenas, espalhados por todo território brasileiro. A grande parte delas está concentrada na região amazônica; depois, a segunda maior concentração está no Nordeste, que possui características diferentes daquelas da região amazônica. Esse número contabiliza tanto os indígenas que vivem nas áreas rurais - Terras Indígenas - $(63,8 \%)$ quanto nas áreas urbanas (36,2 \%). É muito evidente esse trânsito para as áreas urbanas, tendo em vista que muitos in- 
dígenas terminam sua formação fora de suas comunidades, ou seja, fora do contexto em que nasceram e cresceram. Também é importante destacar que, a partir dos anos 90 em diante, é crescente o número de associações indígenas lideradas pelos próprios indígenas, à qual muitas delas mantêm sedes em centros urbanos do país. No entanto, esses índios em contextos urbanos sofrem o estigma da adequação ou não ao estereótipo clássico, criando um conflito de que, por acessar à tecnologia da comunicação, não seriam índios verdadeiros, pois somente seriam índios verdadeiros aqueles que vivem pelados na floresta.

As culturas indígenas, tal qual a cultura não indígena, é dinâmica. A identidade cultural de um povo não se constrói em situação de isolamento; mas, por sua vez, adquire formas em contato com outros povos e culturas diferentes, que mudam e se transformam, algo que não é imanente ou natural, porém, que leva em consideração condicionantes históricos e contextos específicos. As relações de intercâmbio cultural existiam tanto antes da colonização quanto em vários contextos depois; em um sistema de constituição de identidade, as trocas são obrigatórias.

Falando em relações dos povos indígenas com a sociedade brasileira não indígena, a mediação entre elas é de caráter tutelar (cf. ESTATUTO DO ÍNDIO, 1973), o que significa dizer que, pelo Estatuto (formatado durante o Regime de Ditadura Militar), os povos indígenas não possuem capacidade jurídica para certos atos. Mesmo após a Constituição de 1988, o caráter tutelar ainda vigora no âmbito judicial brasileiro, no qual o órgão federal responsável pelos índios é a Funai, que, por sua vez, segue a risca seu papel de instituição tutelar dos povos indígenas brasileiros.

O capítulo quatro tem como título: "Os índios falam tupi guarani, vivem em ocas e cultuam Tupã?". Como já citado anteriormente, os povos indígenas representam uma variedade muito grande de culturas, e isso inclui, certamente, as distintas divindades e modos de cultuar que cada cultura realiza em seus respectivos ritos religiosos. São mais de 200 línguas e 305 povos diferentes, e cada um possui uma organização política, social, cultural e ritual próprias. Então, generalizar e colocar os indígenas em um padrão que nunca existiu é um erro sem precedentes.

O capítulo cinco versa sobre a questão: "Os índios são preguiçosos e primitivos?". O senso comum da sociedade capitalista considera os povos indígenas preguiçosos e primitivos, pois o padrão imposto por essa sociedade hegemônica envolvente coloca o acúmulo de bens para si como algo a ser seguido por todos. As culturas indígenas não seguem esse padrão de acúmulo; o que produzem são suficientes para suprir a sua família e a sua sociedade, o que, de acordo com Marshall Sahlins, citado pelas autoras (COLLET, PALADINO, RUSSO, 2014 apud SAHLINS, 1978), ao invés de ditos primitivos, os indígenas são sociedades afluentes.

O último capítulo discute três argumentos usados contra os povos indígenas: as grandes quantidades de terras para poucos indígenas, que já se considera um motivo para que eles não tenham direito à terra. $\mathrm{O}$ segundo é sobre essas terras serem consideradas improdutivas, o que impede o desenvolvimento e que eles são incapazes de produzir. E o terceiro argumento seria que terras indígenas em faixa de fronteiras são passíveis de invasão, colocando em risco a soberania nacional.

Aqui evidencia-se a importância dada à terra pelos povos indígenas ao contrário do uso da terra pela sociedade capitalista hegemônica. As autoras constroem cinco contra-argumen- 
tos esclarecedores sobre tal ponto. Para começar, os povos indígenas não são donos da terra, e, sim, possuem a posse permanente e inalienável da terra, bens da União destinados ao usufruto dos povos indígenas. As terras podem parecer muito extensas, contudo, não conseguem garantir a sobrevivência de todos os povos indígenas. Essas terras não são improdutivas; os indígenas possuem meios próprios de cultivo e de entendimento da função da terra. Um argumento muito utilizado em razão de interesses financeiros é que as terras indígenas em áreas de fronteiras correm o risco maior de invasão internacional, o que é uma falácia; os indígenas estão apenas preocupados com a preservação de seus territórios. Por último, os povos indígenas não são indivíduos privilegiados pelo governo, porque este legaliza a demarcação de terras, que, em muitos casos, são insuficientes para o desenvolvimento das nações indígenas; outro destaque relevante é que tal processo de demarcação tem uma burocracia extensa, que marca muitas gerações do início ao fim.

Dessa forma, verifica-se que a construção desse livro pelas autoras é um bom instrumento pedagógico, indicando atividades para sensibilização de novas práticas educativas no cumprimento das Leis 11. 645/2008 e 10.639/2003. A primeira, para questionar a visão deturpada da temática indígena normalmente descritas em subsídios de perspectiva colonial; e a segunda, em relação a obrigatoriedade do Ensino da História e da Cultura da África e da Cultura Afro-Brasileira nos currículos e o Estudo da História e das Culturas dos Povos Indígenas.

O livro "Quebrando Preconceitos: subsídios para o ensino das culturas e histórias dos povos indigenas", como uma alternativa de busca de informação para construção de conhecimento na educação básica escolar, cumpre seu objetivo: um compilado de dados e acessos produzidos por indivíduos de diversas etnias espalhadas pelo país; que podem se constituir em novas práticas educativas para quebrar preconceitos - e instaurar novos comportamentos e atitudes de respeito à diversidade e à diferença. Construído em uma linguagem acessível aos educadores, e com informações suficientemente robustas, é um dos caminhos para que as escritas acadêmicas sobre as temáticas indígenas possam passar para materiais com outro foco narrativo e outro público, o dos professores, para que de fato ocorra uma mudança de estereótipos sobre a constituição da identidade de um dos pilares da constituição da identidade do povo e da cultura brasileira.

\section{REFERÊNCIA}

COLLET, C.; PALADINO, M.; RUSSO, K. Quebrando preconceitos: subsídios para o ensino das culturas e histórias dos povos indígenas. Rio de Janeiro: Contra Capa Livraria; Laced, 2014. 